\title{
The Effect of Marketing Culture Aspects of Healthcare Care on Marketing Creativity
}

\author{
Bayad Jamal Ali ${ }^{1}$, Govand Anwar ${ }^{2}$
}

\begin{abstract}
${ }^{1}$ Business Administration Department, Komar University of Science and Technology, Sulaimani 46001, Kurdistan Region - Iraq ${ }^{2}$ Department of Business Administration, College of Administration and Financial Sciences, Knowledge University, 44001 Erbil, Kurdistan Region, Iraq
\end{abstract}

Received: 28 Nov 2020; Received in revised form: 09 Feb 2021; Accepted: 04 Mar 2021; Available online: 30 Mar 2021 (C)2021 The Author(s). Published by Infogain Publication. This is an open access article under the CC BY license (https://creativecommons.org/licenses/by/4.0/).

\begin{abstract}
The main purpose of this study is to analysis the impact of marketing culture aspects of healthcare on marketing creativity. The research was conducted at healthcare sectors in Kurdistan region of Iraq. The researchers employed quantitative research method via using a survey to measure the current study. However, the researchers were able to gather 161 completed questionnaires. The researchers applied hierarchal multiple regression analysis and Sobel test to measure the current study; the findings revealed. The findings proved that there is a positive and significant direct and indirect relationship between cultural value and cultural satisfaction as marketing culture aspects and marketing creativity, moreover cultural experience has a positive and significant mediating role between Cultural value as marketing culture aspect and marketing experience. However, a key element in improving patient-endorsed healthcare systems is an emphasis on cost savings and increased quality, as well as differentiated industry. This are achievable with the acquisition of new technology and well-trained and driven workers who can use their expertise for the good of society in a way that carves out a distinct market that rivals can seldom replicate or copy at a high cost.
\end{abstract}

Keywords-Healthcare, Marketing culture, Cultural value, Cultural satisfaction, Kurdistan region of Iraq.

\section{INTRODUCTION}

Regardless of the nature of organization, current organizations face various environmental conditions, which are characterized by those ones such as their rapid change that posed many challenges on these organizations. In order to adapt to these challenges in a scientific and organized way, the organization has to cope with a new philosophy. Cultural philosophy of marketing is an example that can be adapted to the philosophy mapping of management of these organizations (Mkhize \& Ellis, 2020). It will provide the most important tools to face new environmental conditions. This philosophy has an impact on the profitability of organizations; it is also regarded as one of the leading economic and management philosophies. It calls organizations to adopt an organizational culture. It also encourages ethical practices and activities designed to enhance their competitiveness (Joshi \& Dhar, 2020). At the same time, practicing activities across different levels of the organization aim to provide an exchange marketing knowledge, and then it will get a collective response from it. As a result, there will be a unified goal for all sections and individuals in the organization providing its customers a continuous and superior value. Moreover, it offers a high capacity to adapt and deal with achieving change and transformation through the fulfillment of effective marketing of organizations. In this sense, due to the complicated and rapid changes in marketing, market management puts a greater emphasis on exploring and finding customers' needs and desires (Carah \& Brodmerkel, 2021). It also offers products that are different from what competitors show about their competitive features. For example, if an organization could accomplish this marketing process satisfactorily, as well as focusing on a customer, it leads to an increase in marketing innovation 
through planned and achieved goals. Based on the aforementioned importance, this research has been conducted to encompass these subjects and show their key roles in performing studies organizations that run at hospitals in the Kurdistan region of Iraq (Anwar \& Balcioglu, 2016).

The current study sheds light on both marketing cultural dimensions and their effectiveness that have been employed depending on elements of marketing, inventory through building conceptual and field to know the link between marketing culture and elements of innovative marketing, in addition to analyzing the relationship and abstract effects on these dimensions (Möller et al. 2020). As we can see, contemporary experiences need to accept organizational culture at the same time. These simultaneous experiences make good use of marketing service firms and support them. Proponents of this approach agree that organizational culture plays an important role in commercializing services. The provision and simultaneous use of services, including in-person meetings, will increase the physical and mental integrity of employees and customers (Ali, 2020). In addition to that, Chatterjee \& Kar, (2020) said that the culture of marketing refers to fashions and political behaviors and a timely recipe. The same culture guides employees to challenging behaviors, and the importance of the organization is to glance at marketing and conduct marketing activities. On the other hand, lately, Anwar, (2017) and other researchers and professionals have paid more attention to the fact that they can make cultural services organizational and highly regulated marketing patterns.

Based on "organizational culture", the "marketing culture" can be defined as "a more efficient and effective organizational culture in creating employee behavior, giving exceptional value to buyers of corporate assets and enabling exceptional business results" (Al-Dmour et al. 2020). In addition, Geiger \& Kjellberg, (2021) defined different concepts of culture as attitudes and values of language, customs and manners, technology and material culture, social organizations, aesthetics and religion. Sheth, (2020) has also concluded that global marketing has influenced the cultures of nations and plays an important role in the emergence of global culture. There has been much discussion and debate over the fact that marketing strategies are not an obstacle to the growth of national culture since people act as a great filter. Berger et al. (2020), a well-known marketing expert, has argued that marketing is worthwhile with understanding and appreciating the values that customers are looking for. This, in turn, affects organizations to create and integrate the value of the relationship. Therefore, marketing guides are designed to understand the buyers' needs and offer competitors' suggestions. Thus, it is very important to create superior communication in organizations. According to Ali, (2021), self-knowledge is a source of awesome management, which with knowledge and awareness enables the people present in the company to extract the maximum of all available resources for it. Managing knowledge and awareness by presenting a pre-identifier and coordinated work, to enhance and transform resources into capabilities, plays an excellent role. In the world, when a global competition is increasingly occurring it brings about loyal customers. In order to create these customers through the excellent quality of service and customer satisfaction, it is important to take advantage of the advancement and prosperity of service companies. Having an organization that has satisfied employees will also increase revenue, reduce costs, and provide customer satisfaction (Fields et al. 2021). Anwar, (2017) state that the general idea of marketing, in turn, is believed to be as the key to achieving organizational consistency, such as the ratio of market and profitability, through communication with the determination of needs and desires. Furthermore, it will give you a satisfactory deal, which will have the most impact on the competitor.

According to Van Huy et al. (2020), innovation is a key element for the success of industrial companies. Innovation is about the ability to participate in innovation. This means introducing new processes, products, services, new marketing methods or ideas to improve commercial practices in internal or external business organizations. Van et al. (2020), the link between market orientation and innovation business culture, as well as the function of the name of the trade is evident. They provide the necessary backgrounds to enhance our understanding of market-based performance orientations and cultural searches. These factors contribute to the development and management of special models. García-Granero et al. (2020) defined marketing innovation as "the introduction of a new marketing method that involves significant changes in product design or packaging, product placement, product promotion or determination of the price ". These innovations are implemented by manufacturers under the influence of the introduction of a new or significantly modified marketing concept or strategy. Marketing innovation, for Anwar, (2016) is "new marketing techniques" that relate to strategic organizational behaviors and models. Charoensukmongkol, (202) suggested that marketing innovation is about making new methods. To created and connected communication and give value to buyers and manage affiliation with buyers. According to Anwar \& Ghafoor, (2017), higher education graduates are trained to advance science and knowledge about the effects of the organization. For example, the relationship between creativity and innovation, marketing practices, or creativity 
or innovation and the advancement of the organization, makes peace with the importance of these contradictions (Bejtkovský \& Copca, 2020).

\section{LITERATURE REVIEW}

Ali, (2021) conducted empirical investigation of the connection between the marketing culture of British tourism companies and customer loyalty. The sample selected by the UK-based Association of Hotels and Tourism included in the FAME CD-ROM database. To create the example sketch, two sample criteria were used: companies must be hotel or travel manager and have at least 500 employees. Using this sampling scheme, 250 companies were selected through a stratified random sampling process. This study uses multiple confirmatory regressions. The results showed a moderately strong relationship between marketing culture and customer loyalty. Finally, the implications of the results for tourism managers and the modalities for future research are discussed. Anwar, (2017) reviewed the relationship between two focal constructs in the debate: market orientation and product innovation. 194 small businesses in their sample had been in business for 28 years, employed 267 people and had annual sales of \$ 51 million. About 35\% of small businesses used mass production. The remaining $65 \%$ used tailor-made production technologies for key informants who participated in the survey. $32 \%$ had a marketing title and $68 \%$ had a non-marketing shotgun. This study used multiple regression models. The authors examined the relationship between two key constructs in the debate: market orientation and product innovation.

Bejtkovský \& Copca, (2020) studied the relationship between Market-Oriented and Organizational Culture, sample was 1100 supervisors in 1100 hierarchical cultures at the strategic commerce unit from five distinct industries in Germany, they guaranteed the respondents' skill before the mailing of directing a phone, distinguishing proof of key witnesses on the premise of addresses got from a business supplier. They focused on the key sources included general directors, marketing administrators, and supervisors from other utilitarian zones additionally used the chi-square test. The results show that a market-oriented culture indirectly influences financial performance through market performance and that this relationship is stronger in a very dynamic market. Vlačić, et al. (2021) investigated the level of market culture of the EU individual through the websites of National Tourism Organizations (NTOs) in order to achieve the latest positioning for the EU countries based on the degree of commercialization of the culture, also used the Balanced Scorecard approach, the Coincidence coefficients of Kendal and the analysis of the non-parametric bidirectional variance of Friedman (Anwar \& Qadir, 2017). Demir et al. (2020) focused on what Singapore organizations neglected when they were addressing knowledge management. Furthermore, the work involves collecting, organizing and subdividing information, using both univariate and multivariate measurable tests of the information collected. The result showed that knowledge management should consider not only the technological aspects of the implementation, but also the cultural, leadership and contextual aspects of an organization.

Markova et al. (2020) investigated the relationships between organizational cultures. Business environment, business strategy and functional strategies are rarely explored from a holistic perspective. The food industry contributes around $25 \%$ of GDP and is important in terms of its importance to the economy. Therefore, it recognizes the multilevel effect of cultural orientation - taking into account the functioning of a rational model that combines cultural orientation, business conditions, organizational strategy, functional strategies and performance - which has been proven experimentally. Abdullah et al. (2017) measured the relationship between market orientation and performance using data from 201 international hotels and used multiple regressions. The results show that market orientation is critically correlated with performance metrics - quality of service, consumer loyalty, and employee satisfaction and execution metrics - population, gross operating margin and market share. In particular, the investigation revealed that the immediate effect of market orientation is to stimulate innovation, thus improving the application of judgment, thereby improving the achievement of objectives.

Mesfin et al. (2017) attempted to seek and determine the market orientation and marketing culture of all employees in organizations, to determine the extent to which other members of an organization support or hinder the proper implementation of the marketing concept. A meeting of central assemblies including all staff was conducted in a public library service. A total of eleven meetings of the center took place in nine weeks with 165 stakeholders. A semi-structured approach focused on key issues, such as the role of marketing, the different elements of the marketing mix and the impact of the marketing strategy used. The results showed that while all regions inside this association are focused on marketing, there are different elucidations of marketing and how it ought to be executed. In addition, exploration identified several components that could be relevant to the effective implementation of the marketing concept in public libraries (Anwar, 2017).

Rasulev et al. (2020) mentioned three research questions: (1) Why are some industrial companies more innovative 
than others? (2) What influence does innovation have on business development? (3) Does the relationship between innovativeness and business performance depend on the environmental context? The sample of 1000 companies with annual sales of over $\$ 100$ million with an identifiable marketing manager purchased by Dun \& Bradstreet Information Services, also, factor analysis models have used. Be that as it may, they draw on different hypothetical points of view to create theories that propose market orientation, entrepreneurial orientation, and learning orientation as key predecessors to create, and additionally an immediate connection amongst ingenuity and business execution. A model is formulated and tried that looks at these connections when all is said in done and with regards to fluctuating business sector turbulence. Discoveries affirm the legitimacy of the model and bear the cost of different bits of knowledge on the part of market turbulence in the proposed relationships. Lastly, the implications are offered on the antecedents and consequences of organizational innovativeness (Darvishmotevali et al. 2020). Andavar \& Ali, (2020) evaluated the measurement of product innovation as opposed to the self-reported measures used in innovation research. The study used 152 rose breeders as a sample; To estimate the coefficients in the equation system, ordinary least squares regression (OLS) was used. The results of the survey showed that the owners' innovation capacity was steeped in all the variables of the model and had a positive impact on market orientation, innovation and performance. Another interesting result of exploration is that knowing the customer market has a positive or negative impact on product innovation, depending on whether the creativity of the owner of the new product domain is weak or strong. Chen, (2020) examined a structure in an expanded model of competing values of corporate culture and focused on how organizational culture, market orientation and innovation influence the performance of companies competing in the business- to-business markets. For individual site meetings, spot checks were selected by companies to provide samples of companies based in that country and in the city in which the meetings took place and were exchanged through the country's real trading. The survey used a regression model. The results showed significant differences between countries in the media of all variables studied, and these differences generally reflect the characteristics of national cultures (Hameed \& Anwar, 2018).

Liu et al. (2020) studied the potential impact of service quality, interpersonal relationships, selling task, organization, internal communication, and innovativeness on marketing culture through the use of Webster's standard marketing culture instrument. The above hypotheses have been examined on the basis of the information provided by the Frontline hotel staff in a city in western Turkey. The study area included six five-star hotels with over 1,800 rooms and thirteen four-star hotels with over 1,800 rooms. In the spring of 2001, 750 observations were distributed to Frontline employees. The measurements were subjected to a confirmation factorial analysis. The results showed that the interpersonal relationship; Sales activities, internal communication and innovation have a significant positive impact on the marketing culture, while the quality of the service and organization have no significant impact on the marketing culture. In addition, the results of the confirmatory factor analysis of the six-factor structure have further lent credibility to the marketing culture scale by suppressing various elements of each dimension, excluding innovation (Grier \& Poole, 2020). Mkhize \& Ellis, (2020) investigated alternative models contain different behavioral and cultural behaviors with a causal relationship. A questionnaire was sent to the executive directors of the 1958 Social Administration, group support or artistic organizations in Toronto and Montreal (Canada), as well as structural equation modeling (SEM) general adaptation of each model and the importance of individual relationships in each model. The results showed that a positive relationship between market-oriented behavior and organizational performance is mediated by a marketoriented culture. The survey contributes to the understanding of the hypothetical relationship between culture and market-oriented behavior in non-profit organizations, as well as to administrative procedures aimed at bringing market orientation to this department.

Joshi \& Dhar, (2020) evaluated the conceptualization and empirically tested a model that combines different kinds of strategic orientation and market forces, through organizational learning with revolutionary innovations and business performance. They got the sample as takes after: First, they acquired a framework for testing 2,260 brands of consumer solid and unused products, which were generally used in 48 classifications by the China Marketing and Media Study of Sino-Monitor International Company (2000). Second, they used a stratified sampling test to select scores for review. They isolated the brands in each article class in two sessions on condition of their market share. The Annual General Meeting comprised the 10 highest-priced brands. The second meeting included the remaining brands (Anwar \& Balcioglu, 2016). They chose no less than 3 marks aimlessly from each brand gather in every item classification, for an aggregate of 150 and 250 brands from the first and second gatherings, respectively; as well as they used structural equation modeling. The results show that market orientation fosters innovation that uses advanced technologies and offers greater benefits to traditional customers (ie technology-based innovations), but inhibits 
innovation that targets emerging market segments (for example, market-based innovation). Möller et al. (2020) studied the relationship between learning orientation (LO), market orientation (MO), Human Resources Practices (HRP), innovation and its connection with the performance of organizations. The aim was to demonstrate that human resources and innovation are important mechanisms for conveying the benefits of LO and MO in performance results. Based on extensive literature, a model of relationships is developed and tested empirically using data collected from 220 organizations. Data analyzed by modeling structural equations and / or modeling paths (Anwar, 2017). The essential point is to investigate the direct, indirect and aggregated effects of $\mathrm{LO}$ and $\mathrm{MO}$ on the results of the implementation of human resources and innovation (administrative, process innovation and planned product) as an intermediary. The study deliberately follows the effects of each factor to identify the effects and deviant effects that have occurred. Results HRPs are one of the main mechanisms for transferring the benefits of LO and MO. In some models, this is even more important than innovation. The results also suggest that LO should be considered as an investigation, while $\mathrm{MO}$ is the interface between investigation and abuse and, ultimately, human resources and innovation must be seen as exploitation or implementation problems.

\section{METHODOLOGY}

This research aimed to analysis the impact of marketing culture aspects of healthcare on marketing creativity. The research was conducted at healthcare sectors in Kurdistan region of Iraq. To enable the study to measure marketing creativity at healthcare sectors, the researchers used two marketing culture aspects, first was cultural value as marketing culture aspect and second cultural satisfaction as marketing culture aspect. Moreover, the researcher intended to measure cultural experience as a mediator to measure both marketing culture aspects and find the direct and indirect influence on health care marketing creativity. The researchers employed quantitative research method via using a survey to measure the current study. The questionnaire was distributed randomly among 180 administrative employees of different healthcare sectors in Kurdistan region. However, the researchers were able to gather 161 completed questionnaires. All items in the questionnaire were evaluated by using five point Likert scale ranging from $1=$ Strongly Disagree, $2=$ Disagree, $3=$ Neutral, $4=$ Agree to $5=$ Strongly Agree. After the completion of data gathering, all data were examined by SPSS to find out the influence of marketing culture aspects of healthcare on marketing creativity.

\section{Research Model}

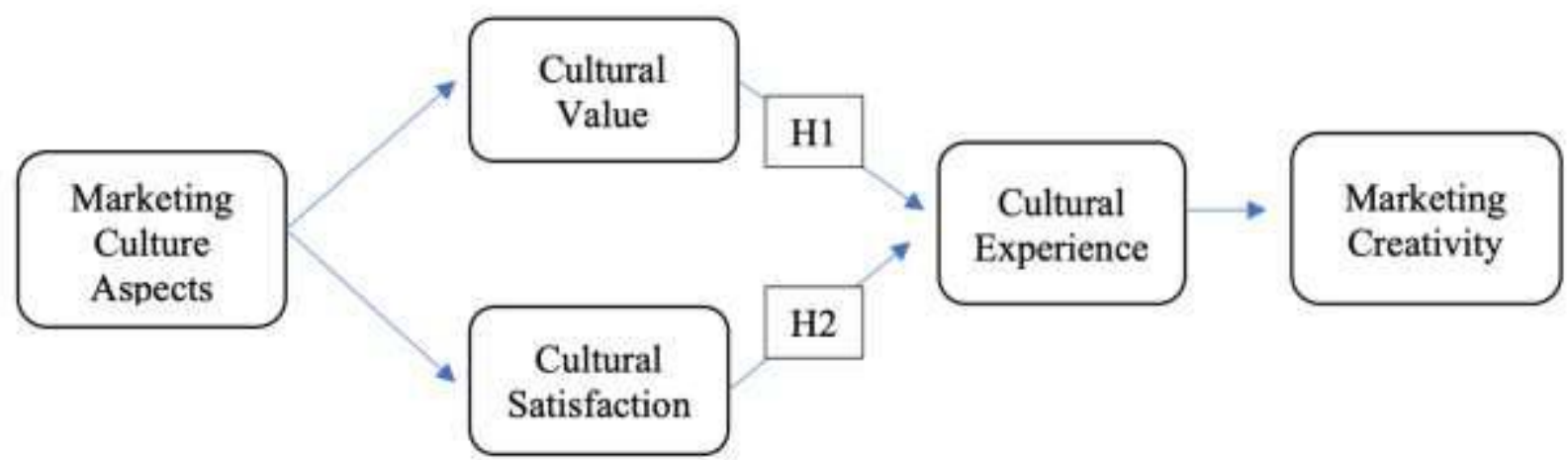

Fig.1: Research Model

\section{Research Hypotheses}

H1: Cultural experience mediates Cultural value as marketing culture aspect with marketing creativity.

$\mathrm{H} 2$ : Cultural experience mediates Cultural satisfaction as marketing culture aspect with marketing creativity.

Table 1- KMO and Bartlett Sphericity Test of Self-rating Items

\begin{tabular}{|l|l|l|l|l|l|}
\hline Factors & $\begin{array}{l}\text { N of } \\
\text { items }\end{array}$ & $n$ & KMO & \multicolumn{2}{|c|}{ Bartlett test } \\
\cline { 4 - 6 } & & & & Chi-Square & Sig \\
\hline Cultural value as marketing culture & 13 & 161 & .667 & 2.071 & .000 \\
\hline
\end{tabular}




\begin{tabular}{|l|l|l|l|l|l|}
\hline $\begin{array}{l}\text { Cultural satisfaction as marketing } \\
\text { culture }\end{array}$ & 14 & 161 & & & \\
\cline { 1 - 3 } Marketing creativity & 14 & 161 & & & \\
\cline { 1 - 3 } Cultural experience & 13 & 161 & & & \\
\hline
\end{tabular}

As we can see in table (1), the result of KMO for all independent variables (cultural value as marketing culture, cultural satisfaction as a marketing culture), cultural experience as mediator and marketing creativity as dependent variable $\mathrm{r}$; is .667 which is higher than .001 this indicates that the sample size used for the current study was more than adequate. Furthermore, the result of Chi-Square is 2155.2 with the significant level .000 .

Table 2: Reliability analysis

\begin{tabular}{|l|l|l|l|}
\hline Variables & N of items & $\mathrm{n}$ & Cronbach's Alpha \\
\hline Cultural value as marketing culture & 13 & 161 & .751 \\
\hline Cultural satisfaction as marketing culture & 14 & 161 & .762 \\
\hline Marketing creativity & 14 & 161 & .781 \\
\hline Cultural experience & 14 & 161 & .731 \\
\hline
\end{tabular}

As seen in table (2), the reliability analysis for 55 items used to measure the influence of independent variables (cultural value as marketing culture, cultural satisfaction as a marketing culture), and marketing creativity as dependent variable also cultural experience as mediator factor. The above 55 questions were distributed as follow; 13 items for Cultural value as marketing culture, 14 items for Cultural satisfaction as marketing culture, 14 items for Marketing creativity, and 14 items for Cultural experience. The researchers applied reliability analysis to find out the reliability for each factor, the findings revealed as follow: as for Cultural value as marketing culture was found the Alpha to be .751 with the sample size of 161 for 13 questions which indicated that all 13 questions used to measure Cultural value as marketing culture were reliable for the current study, as for Cultural satisfaction as marketing culture was found the Alpha to be .762 with the sample size of 161 for 14 questions which indicated that all 14 questions used to measure Cultural satisfaction as marketing culture were reliable for the current study, as for Marketing creativity was found the Alpha to be .781 with the sample size of 161 for 14 questions which indicated that all 14 questions used to measure Marketing creativity were reliable for the current study, and as for Cultural experience was found the Alpha to be .731 with the sample size of 161 for 14 questions which indicated that all 14 questions used to measure Cultural experience were reliable for the current study.

Table 3: Correlation Analysis

\begin{tabular}{|l|l|l|l|l|l|}
\hline \multicolumn{2}{|l|}{ Correlations } & Cultural value & $\begin{array}{l}\text { Cultural } \\
\text { satisfaction }\end{array}$ & $\begin{array}{l}\text { Marketing } \\
\text { creativity }\end{array}$ & $\begin{array}{l}\text { Cultural } \\
\text { experience }\end{array}$ \\
\hline \multirow{4}{*}{ Cultural value } & Pearson Correlation & 1 & & & \\
\cline { 2 - 6 } & Sig. (2-tailed) & & & & \\
\cline { 2 - 7 } & $\mathrm{N}$ & 161 & & & \\
\hline Cultural satisfaction & Pearson Correlation & $.612^{* *}$ & 1 & & \\
\cline { 2 - 7 } & Sig. (2-tailed) & .000 & & & \\
\cline { 2 - 7 } & $\mathrm{N}$ & 161 & 161 & & \\
\hline Marketing creativity & Pearson Correlation & $.631^{* *}$ & $.628^{* *}$ & 1 & \\
\cline { 2 - 7 } & Sig. (2-tailed) & .000 & .000 & & \\
\hline
\end{tabular}




\begin{tabular}{|l|l|l|l|l|l|}
\hline & $\mathrm{N}$ & 161 & 161 & 161 & \\
\hline \multirow{5}{*}{ Cultural experience } & Pearson Correlation & $.578^{* *}$ & $.602^{* *}$ & $.639^{* *}$ & 1 \\
\cline { 2 - 6 } & Sig. (2-tailed) & .000 & .001 & .000 & \\
\cline { 2 - 6 } & $\mathrm{N}$ & 161 & 161 & 161 & 161 \\
\hline \multirow{2}{*}{$* *$. Correlation is significant at the 0.01 level (2-tailed). }
\end{tabular}

As it can be seen in table (3), the correlation analysis between Cultural value as marketing culture, Cultural satisfaction as marketing culture), and Marketing creativity as dependent variable also Cultural experience as mediator factor. The finding revealed that the value of Pearson correlation $\left(\mathrm{r}=.578^{* *}, \mathrm{p}<0.01\right)$, between Cultural value as marketing culture and Marketing creativity this indicated that there is positive and strong correlation between Cultural value as marketing culture and Marketing creativity, the value of Pearson correlation $\left(r=.602^{* *}, p<0.01\right)$, between Cultural satisfaction as marketing culture and Marketing creativity this indicated that there is positive and strong correlation between Cultural satisfaction as marketing culture and Marketing creativity, and the value of Pearson correlation $\left(\mathrm{r}=.639^{* *}, \mathrm{p}<0.01\right)$, between Cultural experience and Marketing creativity this indicated that there is positive and strong correlation between Cultural experience and Marketing creativity,

H1: Cultural experience mediates Cultural value as marketing culture aspect with marketing creativity.

Table 4-Hierarchal Multiple Regression

\begin{tabular}{|c|c|c|c|c|c|c|}
\hline \multicolumn{7}{|c|}{ Coefficients } \\
\hline \multicolumn{2}{|c|}{ Model } & \multicolumn{2}{|c|}{ Unstandardized Coefficients } & \multirow{2}{*}{$\begin{array}{l}\text { Standardized } \\
\text { Coefficients }\end{array}$} & \multirow[t]{2}{*}{$\mathrm{t}$} & \multirow[t]{2}{*}{ Sig. } \\
\hline & & B & Std. Error & & & \\
\hline \multirow[t]{2}{*}{1} & (Constant) & 2.101 & .2231 & & 5.661 & .000 \\
\hline & $\begin{array}{l}\text { Cultural } \\
\text { value }\end{array}$ & .632 & .022 & .637 & 3.522 & .000 \\
\hline \multirow[t]{3}{*}{2} & (Constant) & 1.211 & .189 & & 2.774 & .000 \\
\hline & $\begin{array}{l}\text { Cultural } \\
\text { value }\end{array}$ & .644 & .087 & .647 & 1.822 & .001 \\
\hline & $\begin{array}{l}\text { Cultural } \\
\text { experience }\end{array}$ & 669 & .036 & .672 & 1.252 & .000 \\
\hline & ent & arke & ivity & & & \\
\hline
\end{tabular}

Table (4), demonstrates a hierarchal multiple regression analysis to investigate first research hypothesis which stated that Cultural experience mediates Cultural value as marketing culture aspect with marketing creativity. Concerning model (1) the direct relationship between Cultural value as marketing culture aspect and marketing creativity, the value of $\mathrm{B}=.632$, the value of Beta $=.637$ with $\mathrm{P}$-value $=.000$ this indicated that there is a significant and positive relationship between Cultural value as marketing culture aspect and marketing creativity. As for model (2) which applied multiple regression analysis to find both Cultural value as marketing culture aspect as independent factor and Cultural experience as a mediator factor with marketing creativity as dependent factor, the findings showed that the value of $B=.644$, the value of Beta $=.647$ with $\mathrm{P}$-value .001 as indirect relationship between Cultural value as marketing culture aspect and marketing creativity, on the other hand, the value of $\mathrm{B}=.669$, the value of Beta $=.672$ with P-value .000 as mediation between Cultural experience and marketing creativity. The findings proved that there is a positive and significant direct and indirect relationship between Cultural value as marketing culture aspect and marketing creativity, moreover cultural experience has a positive and significant mediating role between Cultural value as marketing culture aspect and marketing experience. 
Table 5: Sobel Test

\begin{tabular}{|c|c|c|c|c|c|}
\hline & Input: & & Test statistic: & Std. Error: & $p$-value: \\
\hline a & .644 & Sobel test: & 6.87681495 & 0.06265052 & 0 \\
\hline$b$ & .669 & Aroian test: & 6.86823789 & 0.06272875 & 0 \\
\hline$s_{a}$ & .087 & Goodman test: & 6.88542422 & 0.06257218 & 0 \\
\hline & .036 & Reset all & & Calculate & \\
\hline
\end{tabular}

P-value is significant at level 0.005

Table (5), illustrates the findings of Sobel test to find the mediation analysis, the result demonstrates the direct relationship between Cultural value as marketing culture aspect and marketing creativity, P-value $=.0002$ this indicated that there is a significant and positive direct relationship between Cultural value as marketing culture aspect and marketing creativity. Furthermore, P-value is .000 as indirect relationship between Cultural value as marketing culture aspect and marketing creativity.
Moreover, the results proved that there is a positive and significant direct and indirect relationship between Cultural value as marketing culture aspect and marketing creativity, moreover cultural experience has a positive and significant mediating role between Cultural value as marketing culture aspect and marketing creativity.

$\mathrm{H} 2$ : Cultural experience mediates Cultural satisfaction as marketing culture aspect with marketing creativity.

Table 6: Hierarchal Multiple Regression

\begin{tabular}{|c|c|c|c|c|c|c|}
\hline \multicolumn{7}{|c|}{ Coefficients } \\
\hline \multirow{2}{*}{\multicolumn{2}{|c|}{ Model }} & \multicolumn{2}{|c|}{$\begin{array}{l}\text { Unstandardized } \\
\text { Coefficients }\end{array}$} & $\begin{array}{l}\text { Standardized } \\
\text { Coefficients }\end{array}$ & \multirow[t]{2}{*}{$\mathrm{t}$} & \multirow[t]{2}{*}{ Sig. } \\
\hline & & B & Std. Error & Beta & & \\
\hline \multirow[t]{2}{*}{1} & (Constant) & 1.881 & .1007 & & 4.522 & .000 \\
\hline & $\begin{array}{l}\text { Cultural } \\
\text { satisfaction }\end{array}$ & .522 & .022 & .526 & 3.552 & .000 \\
\hline \multirow[t]{3}{*}{2} & (Constant) & 1.121 & .139 & & 2.552 & .000 \\
\hline & $\begin{array}{l}\text { Cultural } \\
\text { satisfaction }\end{array}$ & .578 & .028 & .581 & 2.552 & .000 \\
\hline & $\begin{array}{l}\text { Cultural } \\
\text { experience }\end{array}$ & .539 & .083 & .542 & 2.991 & .000 \\
\hline
\end{tabular}

Table (6), demonstrates a hierarchal multiple regression analysis to investigate second research hypothesis which stated that Cultural experience mediates Cultural satisfaction as marketing culture aspect with marketing creativity. Concerning model (1) the direct relationship between Cultural satisfaction as marketing culture aspect and marketing creativity, the value of $\mathrm{B}=.522$, the value of Beta $=.526$ with $\mathrm{P}$-value $=.000$ this indicated that there is a significant and positive relationship between Cultural satisfaction as marketing culture aspect and marketing creativity. As for model (2) which applied multiple regression analysis to find both Cultural satisfaction as marketing culture aspect as independent factor and Cultural experience as a mediator factor with marketing creativity as dependent factor, the findings showed that the value of $\mathrm{B}$ $=.578$, the value of Beta $=.581$ with P-value .001 as indirect relationship between Cultural satisfaction as marketing culture aspect and marketing creativity, on the other hand, the value of $B=.539$, the value of Beta $=.542$ with P-value .000 as mediation between Cultural experience and marketing creativity. The findings proved that there is a positive and significant direct and indirect relationship 
between Cultural satisfaction as marketing culture aspect and marketing creativity, moreover cultural experience has a positive and significant mediating role between Cultural satisfaction as marketing culture aspect and marketing experience.

Table 7: Sobel Test

\begin{tabular}{|c|c|c|c|c|c|}
\hline & Input: & & Test statistic: & Std. Error: & $p$-value: \\
\hline a & .578 & Sobel test: & 6.19467801 & 0.05029188 & 0 \\
\hline$b$ & .539 & Aroian test: & 6.18807457 & 0.05034555 & 0 \\
\hline$s_{\mathrm{a}}$ & .028 & Goodman test: & 6.20130264 & 0.05023815 & 0 \\
\hline & .083 & Reset all & \multicolumn{3}{|c|}{ Calculate } \\
\hline
\end{tabular}

$\mathrm{P}$-value is significant at level 0.005

Table (7), illustrates the findings of Sobel test to find the mediation analysis, the result demonstrates the direct relationship between Cultural satisfaction as marketing culture aspect and marketing creativity, $\mathrm{P}$-value $=.000$ this indicated that there is a significant and positive direct relationship between Cultural satisfaction as marketing culture aspect and marketing creativity. Furthermore, Pvalue is .000 as indirect relationship between Cultural satisfaction as marketing culture aspect and marketing creativity. Moreover, the results proved that there is a positive and significant direct and indirect relationship between Cultural satisfaction as marketing culture aspect and marketing creativity, moreover cultural experience has a positive and significant mediating role between Cultural satisfaction as marketing culture aspect and marketing creativity.

\section{CONCLUSIONS}

Healthcare providers are enslaved by the immense pressures of lowering treatment prices and rising service quality because most of them are reluctant to invest in the everchanging innovations that aim to do so. Healthcare providers' ability to work successfully in Kurdistan region of Iraq is limited by their limited scale, patients' low knowledge and refusal to try new things, inadequate skills and resource base, rapid technical advances, and failure to transfer strategic grounds to their areas of power. Focusing on a certain geographic area of healthcare increases providers' experience and specialization, resulting in a sustained competitive advantage or a long-term advantage that competitors will find impossible to duplicate. According to the Economics rule of supply and demand, such knowledge and specialization should focus on the expense of treatments and the level of service provided. The researchers applied hierarchal multiple regression analysis and Sobel test to measure the current study; the findings revealed that a hierarchal multiple regression analysis to investigate first research hypothesis which stated that Cultural experience mediates Cultural value as marketing culture aspect with marketing creativity. Concerning model (1) the direct relationship between Cultural value as marketing culture aspect and marketing creativity, the value of $\mathrm{B}=.632$, the value of Beta $=.637$ with $\mathrm{P}$-value $=.000$ this indicated that there is a significant and positive relationship between Cultural value as marketing culture aspect and marketing creativity. As for model (2) which applied multiple regression analysis to find both Cultural value as marketing culture aspect as independent factor and Cultural experience as a mediator factor with marketing creativity as dependent factor, the findings showed that the value of $\mathrm{B}$ $=.644$, the value of Beta $=.647$ with P-value .001 as indirect relationship between Cultural value as marketing culture aspect and marketing creativity, on the other hand, the value of $\mathrm{B}=.669$, the value of Beta $=.672$ with P-value .000 as mediation between Cultural experience and marketing creativity. The findings proved that there is a positive and significant direct and indirect relationship between Cultural value as marketing culture aspect and marketing creativity, moreover cultural experience has a positive and significant mediating role between Cultural value as marketing culture aspect and marketing experience. Moreover, it was found that the direct relationship between Cultural value as marketing culture aspect and marketing creativity, P-value $=.0002$ this indicated that there is a significant and positive direct relationship between Cultural value as marketing culture aspect and marketing creativity. Furthermore, Pvalue is .000 as indirect relationship between Cultural value as marketing culture aspect and marketing creativity. Moreover, the results proved that there is a positive and significant direct and indirect relationship between Cultural value as marketing culture aspect and marketing creativity, 
moreover cultural experience has a positive and significant mediating role between Cultural value as marketing culture aspect and marketing creativity. On the other hand, the hierarchal multiple regression analysis to investigate second research hypothesis which stated that Cultural experience mediates Cultural satisfaction as marketing culture aspect with marketing creativity. Concerning model (1) the direct relationship between Cultural satisfaction as marketing culture aspect and marketing creativity, the value of $\mathrm{B}=$ .522 , the value of Beta $=.526$ with $\mathrm{P}$-value $=.000$ this indicated that there is a significant and positive relationship between Cultural satisfaction as marketing culture aspect and marketing creativity. As for model (2) which applied multiple regression analysis to find both Cultural satisfaction as marketing culture aspect as independent factor and Cultural experience as a mediator factor with marketing creativity as dependent factor, the findings showed that the value of $\mathrm{B}=.578$, the value of Beta $=.581$ with P-value .001 as indirect relationship between Cultural satisfaction as marketing culture aspect and marketing creativity, on the other hand, the value of $B=.539$, the value of Beta $=.542$ with P-value .000 as mediation between Cultural experience and marketing creativity. The findings proved that there is a positive and significant direct and indirect relationship between Cultural satisfaction as marketing culture aspect and marketing creativity, moreover cultural experience has a positive and significant mediating role between Cultural satisfaction as marketing culture aspect and marketing experience. As for Sobel test was found that the direct relationship between Cultural satisfaction as marketing culture aspect and marketing creativity, $\mathrm{P}$-value $=.000$ this indicated that there is a significant and positive direct relationship between Cultural satisfaction as marketing culture aspect and marketing creativity. Furthermore, P-value is .000 as indirect relationship between Cultural satisfaction as marketing culture aspect and marketing creativity. Moreover, the results proved that there is a positive and significant direct and indirect relationship between Cultural satisfaction as marketing culture aspect and marketing creativity, moreover cultural experience has a positive and significant mediating role between Cultural satisfaction as marketing culture aspect and marketing creativity. However, a key element in improving patient-endorsed healthcare systems is an emphasis on cost savings and increased quality, as well as differentiated industry. This are achievable with the acquisition of new technology and well-trained and driven workers who can use their expertise for the good of society in a way that carves out a distinct market that rivals can seldom replicate or copy at a high cost.

The findings suggest that healthcare standardizes service offerings, educates workers, and places a premium on teamwork. They adjust their prices, recruit local workers, and help with local research and development. The standardizing elements of the initiative are based on the healthcare delivery definition, while the adaptation problems are focused on marketing strategy. This mix of adaptation and standardization is influenced by local culture and leads to the creation of trust and networks, making the offering tangible and straightforward. Formal networks with government, regulators, foreign organisations, physicians, and students concentrate on international problems, while informal networks are embedded in the local context and help to establish the credibility of service providers. As a result, this network expansion has an effect on the firm's trustworthiness and tends to resolve the intangibility and heterogeneity of the service offering. Culture is important for services marketing because it contributes to a deeper understanding of which facets of the offering can be standardized/adapted, as well as the growth of trust and networks that sustain the international process by increasing homogeneity and tangibility.

\section{CONTRIBUTION}

To overcome issues of intangibility and heterogeneity of programs, our research contributes to the international services marketing literature by creating a model of internationalization of health services marketing focused on adaptation/standardization, confidence, and network. The research has management ramifications as well. Managers should know that selling people-processing facilities necessitates the creation of local networks in order to achieve confidence and credibility in the local market, as we understand it.

\section{MANAGERIAL IMPLICATIONS}

The following recommendations are boldly made in the light of the preceding findings.

- Healthcare providers should focus on specific business segments because specialization decreases job complexities, prices, and time; carves out an enviable niche; and distinguishes a company's activities from others.

- Since healthcare providers are unable to afford much of the innovations that boost procedures and minimize prices, the government will be able to assist them by bank facilities.

- Healthcare providers in the Western world are urged to collaborate with their technologically superior peers so they can demonstrate openness in their overall dealings. 


\section{LIMITATIONS}

This analysis is constrained by the fact that it is based on only one scenario. Comparative experiments of healthcare cases in other distant countries to the Kurdistan region of Iraq may be performed to assess the conceptual model. The findings of the case studies should be compared to the findings of the current research to get a better understanding of how international health-care promotion works. A crosssectional analysis is useful for examining perceptions about, and perceived costs and benefits of, multinational companies' local adaptation while selling services internationally. In addition, a comparison of international marketing for complicated and moderately complex services will show how services can be planned and distributed to global markets.

\section{REFERENCES}

[1] Mkhize, S., \& Ellis, D. (2020). Creativity in marketing communication to overcome barriers to organic produce purchases: The case of a developing nation. Journal of Cleaner Production, 242, 118415.

[2] Joshi, G., \& Dhar, R. L. (2020). Green training in enhancing green creativity via green dynamic capabilities in the Indian handicraft sector: The moderating effect of resource commitment. Journal of Cleaner Production, 267, 121948.

[3] Alia, B. J. Consumer attitudes towards healthy and organic food in the Kurdistan region of Iraq. Journal of Growing Science, 1-8.

[4] Carah, N., \& Brodmerkel, S. (2021). Alcohol marketing in the era of digital media platforms. Journal of studies on alcohol and drugs, 82(1), 18-27.

[5] Anwar, K., \& Balcioglu, H. (2016). The relationship between transformational leadership characteristics and effectiveness: A case study of construction companies in Erbil. International Journal of Science Technology and Management, 5(2), 250-256.

[6] Möller, K., Nenonen, S., \& Storbacka, K. (2020). Networks, ecosystems, fields, market systems? Making sense of the business environment. Industrial Marketing Management, 90, 380-399.

[7] Ali, B. (2020). Impact of COVID-19 on Consumer Buying Behavior Toward Online Shopping in Iraq. Ali, BJ (2020). Impact of COVID-19 on consumer buying behavior toward online shopping in Iraq. Economic Studies Journal, 18(42), 267-280.

[8] Chatterjee, S., \& Kar, A. K. (2020). Why do small and medium enterprises use social media marketing and what is the impact: Empirical insights from India. International Journal of Information Management, 53, 102103

[9] Anwar, K. (2017). Factors affecting stock exchange investment in kurdistan. The International Journal of Accounting and Business Society, 25(1), 32-37.

[10] Al-Dmour, H. H., Asfour, F., Al-Dmour, R., \& Al-Dmour, A. (2020). The Effect of Marketing Knowledge Management on Bank Performance Through Fintech
Innovations: A Survey Study of Jordanian Commercial Banks. Interdisciplinary Journal of Information, Knowledge, and Management, 15, 203-225.

[11] Geiger, S., \& Kjellberg, H. (2021). Market mash ups: The process of combinatorial market innovation. Journal of Business Research, 124, 445-457.

[12] Sheth, J. N. (2020). Borderless media: Rethinking international marketing. Journal of International Marketing, 28(1), 3-12.

[13] Anwar, G., \& Shukur, I. (2015). the impact of recruitment and selection on job satisfaction: Evidence from private school in Erbil. International Journal of Social Sciences \& Educational Studies, 1(3), 4-13.

[14] Berger, J., Humphreys, A., Ludwig, S., Moe, W. W., Netzer, O., \& Schweidel, D. A. (2020). Uniting the tribes: Using text for marketing insight. Journal of Marketing, 84(1), 1-25.

[15] Ali, B. J. (2021). Impact of consumer animosity, boycott participation, boycott motivation, and product judgment on purchase readiness or aversion of Kurdish consumers in Iraq. Journal of Consumer Affairs

[16] Anwar, G., \& Shukur, I. (2015). Job satisfaction and employee turnover intention: A case study of private hospital in Erbil. International Journal of Social Sciences \& Educational Studies, 2(1), 73.

[17] Fields, Z., Abdullah, Z. M., Musisi, A. N., \& Mitchley, N. K. (2021). Using Collective Creativity and Industry 4.0 Technology to Reduce the Negative Impact of a Pandemic on Entrepreneurs. In Handbook of Research on Using Global Collective Intelligence and Creativity to Solve Wicked Problems (pp. 133-155). IGI Global.

[18] Anwar, K. (2017). Analyzing the conceptual model of service quality and its relationship with guests'satisfaction: a study of hotels in erbil. The International Journal of Accounting and Business Society, 25(2), 1-16.

[19] Van Huy, N., Thu, N. T. H., Anh, N. L. T., Au, N. T. H., Cham, N. T., \& Minh, P. D. (2020). The validation of organisational culture assessment instrument in healthcare setting: results from a cross-sectional study in Vietnam. BMC public health, 20(1), 1-8.

[20] Van Esch, P., von der Heidt, T., Frethey-Bentham, C., \& Northey, G. (2020). The Effect of marketing simulations on student engagement and academic outcomes. Marketing Education Review, 30(1), 43-56.

[21] Anwar, K. (2016). Comparison between cost leadership and differentiation strategy in agricultural businesses. Custos E Agronegocio on Line, 12(2), 212-231.

[22] García-Granero, E. M., Piedra-Muñoz, L., \& GaldeanoGómez, E. (2020). Measuring eco-innovation dimensions: The role of environmental corporate culture and commercial orientation. Research Policy, 49(8), 104028.

[23] Charoensukmongkol, P. (2020). The efficacy of cultural intelligence for adaptive selling behaviors in cross-cultural selling: The moderating effect of trait mindfulness. Journal of Global Marketing, 33(3), 141-157.

[24] Anwar, K., \& Ghafoor, C. (2017). Knowledge management and organizational performance: A study of private universities in Kurdistan. International Journal of Social Sciences \& Educational Studies, 4(2), 53. 
[25] Bejtkovský, J., \& Copca, N. (2020). The Employer Branding Creation and HR Marketing in Selected Healthcare Service Providers. Management \& Marketing. Challenges for the Knowledge Society, 15(1), 95-108.

[26] Ali, B. J. (2021). Assessing (The impact) of advertisement on customer decision making: Evidence from an educational institution. Ali, BJ (2021). Assessing (The impact) of advertisement on customer decision making: Evidence from an educational institution. Afak for Science Journal, 6(01), 267-280

[27] Anwar, K. (2017). The Role of Effective Leadership in Crisis Management: Study of Private Companies in Kurdistan. Qalaai Zanist Scientific Journal, 2(4), 326-338.

[28] Bejtkovský, J., \& Copca, N. (2020). The Employer Branding Creation and HR Marketing in Selected Healthcare Service Providers. Management \& Marketing. Challenges for the Knowledge Society, 15(1), 95-108.

[29] Vlačić, B., Corbo, L., e Silva, S. C., \& Dabić, M. (2021). The evolving role of artificial intelligence in marketing: A review and research agenda. Journal of Business Research, 128, 187-203.

[30] Anwar, K., \& Qadir, G. H. (2017). A Study of the Relationship between Work Engagement and Job Satisfaction in Private Companies in Kurdistan. International Journal of Advanced Engineering, Management and Science, 3(12), 239944.

[31] Demir, A., Maroof, L., Khan, N. U. S., \& Ali, B. J. (2020). The role of E-service quality in shaping online meeting platforms: a case study from higher education sector. Journal of Applied Research in Higher Education, 128

[32] Markova, M., Modliński, A., \& Pinto, L. M. (2020). Creative or analitical way for career development? Relationship marketing in the field of international business education. Creativity Studies, 13(1), 99-113.

[33] Anwar, G., \& Shukur, I. (2015). The Impact of Training and Development on Job Satisfaction: A Case Study of Private Banks in Erbil. International Journal of Social Sciences \& Educational Studies, 2(1), 65

[34] Abdullah, M. S., Toycan, M., \& Anwar, K. (2017). The cost readiness of implementing e-learning. CUSTOS E AGRONEGOCIO ON LINE, 13(2), 156-175

[35] Mesfin, D., Woldie, M., Adamu, A., \& Bekele, F. (2020). Perceived organizational culture and its relationship with job satisfaction in primary hospitals of Jimma zone and Jimma town administration, correlational study. BMC Health Services Research, 20, 1-9.

[36] Rasulev, A., Yakhshieva, M., Yusupov, R., Abdullaeva, M., \& Otaboev, F. (2020). The role of islamic banking in the transformation of international corporations as a reflection of modern globalization and migration. Архив научных исследований, (20), 1-10.

[37] Anwar, K. (2017). Leading Construction Project Teams: The Effectiveness of Transformational Leadership in Dynamic Work Environments in Kurdistan. International Journal of Advanced Engineering, Management and Science, 3(10), 239925
[38] Darvishmotevali, M., Altinay, L., \& Köseoglu, M. A. (2020). The link between environmental uncertainty, organizational agility, and organizational creativity in the hotel industry. International Journal of Hospitality Management, 87, 102499.

[39] Andavar, V., \& Ali, B. (2020). Rainwater for Water Scarcity Management: An Experience of Woldia University (Ethiopia). ANDAVAR, V., ALI, BJ, \& ALI, SA (2020). Rainwater for Water Scarcity Management: An Experience of Woldia University (Ethiopia). The Journal of Business Economics and Environmental Studies, 10(4), 29-34

[40] Chen, C. L. (2020). Cross-disciplinary innovations by Taiwanese manufacturing SMEs in the context of Industry 4.0. Journal of Manufacturing Technology Management.

[41] Hameed, A. A., \& Anwar, K. (2018). Analyzing the Relationship between Intellectual Capital and Organizational Performance: A Study of Selected Private Banks in Kurdistan. International Journal of Social Sciences \& Educational Studies, 4(4), 39.

[42] Liu, H. Y., Chang, C. C., Wang, I. T., \& Chao, S. Y. (2020). The association between creativity, creative components of personality, and innovation among Taiwanese nursing students. Thinking Skills and Creativity, 35, 100629.

[43] Grier, S. A., \& Poole, S. M. (2020). Will Social Marketing Fight for Black Lives? An Open Letter to the Field. Social Marketing Quarterly, 26(4), 378-387. 